\title{
Combining breastfeeding and work: findings from the Epifane population-based birth cohort
}

\author{
Katia Castetbon ${ }^{1,2^{*}}$, Julie Boudet-Berquier ${ }^{2,3}$ and Benoit Salanave ${ }^{2}$
}

\begin{abstract}
Background: Return to work is often cited as a reason for early cessation of breastfeeding (BF). Our objectives were to study the time span during which women employed prior to pregnancy returned to work according to BF duration category, and to identify sociodemographic, behavioral and pregnancy characteristics of women who continued BF after returning to work.

Methods: Information on BF mode and work status was prospectively collected in a French nation-wide birth cohort up to 1 year after delivery. Time of return to work according to BF category was addressed using KaplanMeier curves and Poisson regression adjusted on co-variates. Multiple logistic regression enabled to identify characteristics associated with the combination of BF with work.

Results: Among 2480 women holding jobs prior to pregnancy, 82.0\% returned to work within a year postpartum. Women who breastfed $>4$ months returned at median of 6.5 months, whereas those who did not breastfeed at all returned to their jobs at 4.0 months, those who had breastfed for less than 1 month returned at 4.5 months, and those who had breastfed for 1 to 4 months returned at 4.0 months. Around one-third of women (34.5\%) combined BF and work, and breastfed for a longer duration (median: 213 days, vs. 61 days for women who stopped BF before returning to work). Women born outside of France or who were self-employed were more likely to combine BF and work, while intermediate employees, manual workers, women who quitted smoking during pregnancy, who had smoked before and during pregnancy, or who had given birth by cesarean section were less likely to combine $\mathrm{BF}$ and work.

Conclusion: Women who had breastfed for less than 4 months, or not at all, returned to their jobs at comparable times. This suggests that working women should be encouraged to breastfeed, even for a short duration. Moreover, only one-third of working women succeeded in combining BF and work, highlighting the need for a support system that would encourage flexibility.
\end{abstract}

Keywords: Birth cohort, Breastfeeding, Employment, Maternity leave, Mothers, Social determinants

\section{Background}

Breastfeeding (BF) initiation has been shown to be insufficient, and mean BF duration falls under the recommended 6-month duration in most developed countries,

\footnotetext{
*Correspondence: katia.castetbon@ulb.ac.be

'Université libre de Bruxelles, Ecole de Santé Publique, Centre de Recherche en Epidémiologie, Biostatistique et Recherche Clinique, CP 598, Université libre de Bruxelles, Route de Lennik, 808, B-1070 Bruxelles, Belgium

${ }^{2}$ Equipe de Surveillance et d'Epidémiologie Nutritionnelle (Esen), Santé

Publique France, Université Paris 13, Centre de Recherche en Epidémiologie

et Statistiques, COMUE Sorbonne Paris Cité, Bobigny, France

Full list of author information is available at the end of the article
}

despite its acknowledged benefits and public health actions [1]. Among several determinants, increasing attention has been paid to return to work (RTW) as a major constraint to initiate and continue BF [2-4]. Numerous previous studies consistently concluded that RTW before 12-16 weeks, compared with later or not at all, was associated with shorter BF duration [5-15]. Indeed, women themselves mentioned RTW as a reason for stopping BF [16-20], though not in all settings [21, 22], probably due to cultural norms and work support backgrounds. Moreover, women who planned to work after

(c) The Author(s). 2020 Open Access This article is distributed under the terms of the Creative Commons Attribution 4.0 International License (http://creativecommons.org/licenses/by/4.0/), which permits unrestricted use, distribution, and 
giving birth often did not begin BF, by anticipation. However, conclusions between studies are inconsistent [2, 7, 11-13, 23-27]. Methodological weaknesses, i.e. cross-sectional design or inaccurate data collection, limit our understanding of mechanisms involved in this phenomenon [28]. In addition, a potential bilateral relationship makes it difficult to interpret causality direction. Use of RTW as the outcome, and taking into account its confounders, could help to gain better insight into the complex relationship between BF behavior and RTW.

Although the relationship between RTW and BF cessation has been frequently examined, the combination of $\mathrm{BF}$ and work has rarely been studied in the general population $[29,30]$. This type of behavior could be a strategy for encouraging BF and its duration. Solutions such as teleworking, flexible working hours and access to a room available for $\mathrm{BF}$ or for pumping milk would act as motivations for women to continue BF after RTW $[30,31]$. Nevertheless, along with workplace conditions, characteristics of women who successfully combined BF and work have thus far been rarely described in Western countries.

Our objectives were to study the time span during which women employed prior to pregnancy returned to work according to BF duration category, and to identify sociodemographic, behavioral and pregnancy characteristics of women who continued BF after returning to work. This research was carried out in France, where most women have access to paid maternity leave, usually lasting around 12 weeks.

\section{Methods}

\section{Population and follow-up}

The inclusion process in the Epifane cohort, which was carried out between January and April 2012, has been described previously [32]. Two-stage random sampling was used. First, 136 maternity units were randomly selected proportionally to the yearly number of deliveries, stratified according to private/public status, equipment level of the maternity unit and five geographic areas. Second, after having checked for eligibility criteria, midwives included 25 mother-infant dyads 1 or 2 days after birth. Inclusion criteria were as follows: mothers aged 18 or over, not living in an institution, French-speaking or with access to help filling out questionnaires; gestational age at delivery $\geq 33$ amenorrhea weeks; and no severe newborn pathology that required transfer to a specialized neonatology unit just after delivery. Follow-up was planned to last 12 months for each dyad. Mothers were interviewed by phone at $1,4,8$ and 12 months. At the same time, they also filled in self-questionnaires using internet or regular mail.

\section{Measurements}

Employment prior to pregnancy was reported at the maternity unit. At each further contact, women were asked whether they had returned to work and, if so, the exact date of return. In addition, their occupation was described 1 month after birth using a 10-category variable based on classification used by the French National Institute of Statistics and Economic Studies (https://www. insee.fr/fr/information/2400059) and grouped into 4 categories:

- "Farmers, artisans, merchants, etc.", mainly including independent occupations (i.e. unsalaried);

- "Management", including executive and managerial positions and other post-graduate occupations;

- "Intermediate employees", i.e. those who attained an intermediate university level and work as teachers, health professionals (except for medical doctors, who were included in the "management" category), administrative employees, forewomen, etc.;

- "Manual workers", grouping together occupations mainly involving factory production jobs.

BF status was assessed at the maternity unit and at each further follow-up appointment. Mothers were asked whether they were currently giving breastmilk, formula and all other liquids (and foods after 1 month). If they had been breastfeeding at the previous interview and had then begun to give formula or other liquids/ foods, the infant's age when they had begun was collected, as was the infant's age (in months and weeks) when they stopped giving breastmilk or formula. Altogether, this information was used to define BF status over time using WHO definitions [33]: exclusive BF (no liquid other than breastmilk, except for vitamins and medication), formula or mixed BF (formula and breastmilk). "Any BF" (ABF) included infants who received breastmilk, exclusively or not, pumped or not. At 1-, 4and 8-month interviews, women were questioned about the number of maternal milk feeds (including expressed milk) during the past few weeks, and about where the child usually slept at night.

Maternal characteristics were collected at birth (age, marital status, smoking before and during pregnancy, body weight and height before pregnancy) and at the 1month interview (country of birth, education, parity). Information on birthweight (in grams), gestational age (in full amenorrhea weeks) and mode of delivery (vaginal/ cesarean section) was collected by midwives in the medical records.

\section{Statistical analyses}

Analyses are here limited to women employed before pregnancy, who gave birth to a singleton, and without 
missing data regarding BF mode at birth. Mode of feeding at birth was not known for 3 women. Dates of BF cessation $(n=102)$ and of RTW $(n=109)$ were imputed using medians of the interval between the last date of $\mathrm{BF}$ (or no work) and the first follow-up with changed status (no BF or RTW) (12 months for those lost to follow-up). In addition, RTW time was imputed using linear regression in 126 women who returned to work before the end of follow-up, but without a known interval. Other covariates (age, education, occupation, marital status, birthplace, parity, body weight status before pregnancy, smoking status, birthweight, gestational age, and mode of delivery) were also imputed, thereby limiting selection bias due to non-random missing values. Sensitivity analyses were also performed using non-imputed variables for RTW time and ABF duration.

After computing initial probabilities of inclusion, a marginal calibration method was used to estimate final weights. Calibration involved percentages observed in the French National Perinatal Survey 2010 for age, marital status, education and type of pregnancy [34]. We used the "svyset" command (Stata ${ }^{\circ}$ V.12) for taking into account the 2-stage sampling design and final weights in all analyses.

We first described the percentage of women returning to work during the first year after birth, and distribution of RTW time (25th, 50th and 75th percentiles) according to co-variate categories. Differences between categories were tested using the adjusted Wald test. To facilitate interpretation, we estimated RTW time according to the following ABF duration category, defined consistently with distribution observed in our sample: day 0 (no $\mathrm{ABF}$ ), 1-28 days (short duration), 1-4 months (intermediate duration) and $>4$ months (rather long duration). Kaplan-Meier curves of the probability of RTW over time according to these ABF categories were drawn. Since the hypothesis of risk proportionality was not met, Poisson regressions were used to estimate incidence rate ratios (IRR) of RTW time, in each ABF category, compared to no ABF. After univariate analyses, adjusted analysis included all co-variates for which time of RTW was variable, with a $p$-value $<0.20$ in univariate analyses. As a complement, Poisson regression of the RTW time, including ABF duration as a continuous independent variable, was performed.

The second part of the analyses focused on women likely to combine $\mathrm{ABF}$ and work during the first year, i.e. women who breastfed at birth and returned to work within the first year. A combination of ABF and RTW was defined by date of $\mathrm{ABF}$ cessation later than the date of RTW (or no ABF cessation within the year of followup). In order to identify characteristics associated with a combination of $\mathrm{ABF}$ and work, we used logistic regression. For the dependent variable (combination of $\mathrm{ABF}$ and work), the comparison group included women who had stopped ABF before RTW. Selection of variables to be included in multivariate modelling was based on a $p$ value $<0.20$ in univariate logistic regressions. Manual backward strategy was used to identify the final model that included statistically significant co-variates $(p<$ $0.05)$. However, a co-variate with a $p$-value $\geq 0.05$ might be kept if removing it modified the OR of other covariates by over $10 \%$.

\section{Results}

A total of 3368 women were included in the Epifane cohort. Analyses regarding time of RTW were carried out in the 2480 women who worked prior to pregnancy. Characteristics associated with a combination of $\mathrm{ABF}$ and work were analyzed in the 1487 women who had worked before pregnancy and who returned to work within a year after delivery.

\section{Time of return to work in women who had worked prior to pregnancy}

Characteristics of women and distribution of time at which they returned to work are presented in Table 1. A total of $82.0 \%$ of employed women returned to work within 1 year. Median time of RTW was 5.3 months (25th percentile: 3.1 months -75 th percentile: 8.8 months). The lowest percentages of RTW within 1 year were observed in women aged 35 or older, born outside of France, married, with elementary/middle school education, manual workers, obese women, smokers before and during pregnancy, or women having had 3 or more children (Table 1). The longest median times of RTW were observed in those same categories and in overweight women (Table 1). Percentages of RTW were comparable according to the mode of delivery (vaginal: 82.0\%; cesarean section: $82.2 \% ; p=0.93$ ), gestational age ( $\geq 37$ weeks: $82.0 \%$; $33-36$ weeks: $81.7 \% ; p=0.95$ ) and low birthweight (no: $81.9 \%$; yes: $86.4 \% ; p=0.32$ ).

Characteristics statistically associated with BF duration categories were: age, birthplace, matrimonial status, education, occupation before pregnancy, smoking and parity (Additional Table 1). Body weight before pregnancy, mode of delivery, gestational age and birthweight were not associated with BF duration categories.

\section{Time of return to work according to breastfeeding duration}

Since mean RTW time was statistically comparable between exclusive BF and mixed BF at birth (207 days (95\%CI: 192-223) vs. 202 days (195-209)), subsequent analyses were based on ABF. Percentages of RTW within 1 year were $85.1 \%$ in women who did not breastfeed at all, $83.0 \%$ in women who breastfed at birth but for less than 1 month, $85.3 \%$ in women who breastfed for $1-4$ 
Table 1 Characteristics of women who worked before pregnancy - Epifane Birth Cohort, $2012(n=2480)$

\begin{tabular}{|c|c|c|c|c|c|c|}
\hline & $n$ & $\%^{a}$ & Return to & & & \\
\hline & & & $\%$ before & Time & & \\
\hline & & & & 25 th & Median & 75th \\
\hline Age & & & $p=0.04$ & & $p<0.001$ & \\
\hline $18-24 y$ & 220 & 11.3 & 85.5 & 88 & 120 & 241 \\
\hline $25-29$ y & 799 & 33.0 & 83.7 & 93 & 134 & 246 \\
\hline $30-34$ y & 964 & 34.7 & 82.0 & 98 & 170 & 270 \\
\hline$\geq 35$ y & 497 & 21.0 & 77.6 & 108 & 187 & 323 \\
\hline Birthplace & & & $p<0.001$ & & $p=0.01$ & \\
\hline Abroad & 200 & 14.1 & 71.4 & 105 & 210 & 416 \\
\hline France & 2280 & 85.9 & 83.8 & 95 & 152 & 249 \\
\hline Matrimonial status & & & $p=0.004$ & & $P<0.001$ & \\
\hline Married & 1079 & 46.7 & 79.4 & 99 & 177 & 300 \\
\hline Unmarried & 1401 & 53.3 & 84.3 & 93 & 141 & 248 \\
\hline Education & & & $p<0.001$ & & $p=0.054$ & \\
\hline Elementary / Middle school & 363 & 15.0 & 73.8 & 95 & 188 & 416 \\
\hline High school & 580 & 23.1 & 76.7 & 95 & 168 & 334 \\
\hline University & 1537 & 61.9 & 86.0 & 96 & 151 & 229 \\
\hline Occupation before pregnancy & & & $p<0.001$ & & $p=0.001$ & \\
\hline Farmers, artisans, merchants & 74 & 2.8 & 85.2 & 56 & 96 & 170 \\
\hline Managers & 546 & 22.4 & 88.9 & 97 & 147 & 214 \\
\hline Intermediate employees & 1629 & 65.6 & 81.3 & 97 & 162 & 277 \\
\hline Manual workers & 231 & 9.2 & 69.3 & 100 & 210 & 416 \\
\hline Body weight status before pre & & & $p=0.001$ & & $p=0.004$ & \\
\hline Thin & 178 & 7.3 & 82.2 & 97 & 165 & 282 \\
\hline Normal weight & 1661 & 67.0 & 84.0 & 96 & 149 & 245 \\
\hline Overweight & 433 & 17.0 & 79.4 & 98 & 189 & 305 \\
\hline Obese & 208 & 8.7 & 71.9 & 91 & 186 & 416 \\
\hline Smoking & & & $p=0.001$ & & $p=0.07$ & \\
\hline No & 1691 & 69.6 & 82.5 & 96 & 161 & 264 \\
\hline Quit during pregnancy & 425 & 16.5 & 86.0 & 93 & 134 & 239 \\
\hline Before \& during pregnancy & 364 & 13.9 & 74.9 & 100 & 180 & 416 \\
\hline Parity & & & $p<0.001$ & & $p<0.001$ & \\
\hline 1 & 1115 & 46.0 & 90.2 & 90 & 118 & 210 \\
\hline 2 & 1020 & 40.1 & 77.6 & 98 & 179 & 311 \\
\hline$\geq 3$ & 345 & 13.9 & 67.7 & 159 & 227 & 416 \\
\hline
\end{tabular}

${ }^{a}$ Weighted percentages in each category

months and $77.1 \%$ in those who breastfed for more than 4 months $(p=0.0002)$. Kaplan-Meier curves (Fig. 1) showed no difference in timing of RTW between the first three categories of ABF duration. Only women who breastfed for more than 4 months returned to work much later: at a median of 198 days (25th percentile: 120 days - 75th percentile: 333 days) versus 122 (89239), 137 days (91-242) and 121 days (93-212) for the other categories, respectively.
After adjustment, Poisson regression showed that time of RTW was $31 \%$ later in women who had been breastfeeding for more than 4 months than for women who did not breastfeed at all (Table 2). Women falling within the shortest $\mathrm{BF}$ duration categories (<1 month or 1-4 months) returned to work after a time period similar to that of women who did not breastfeed at all (aIRR: 1.07 [0.99-1.15] and 1.05 [0.97-1.13], respectively). Characteristics such as being born abroad (1.10 [1.01-1.20]), education lower than university 


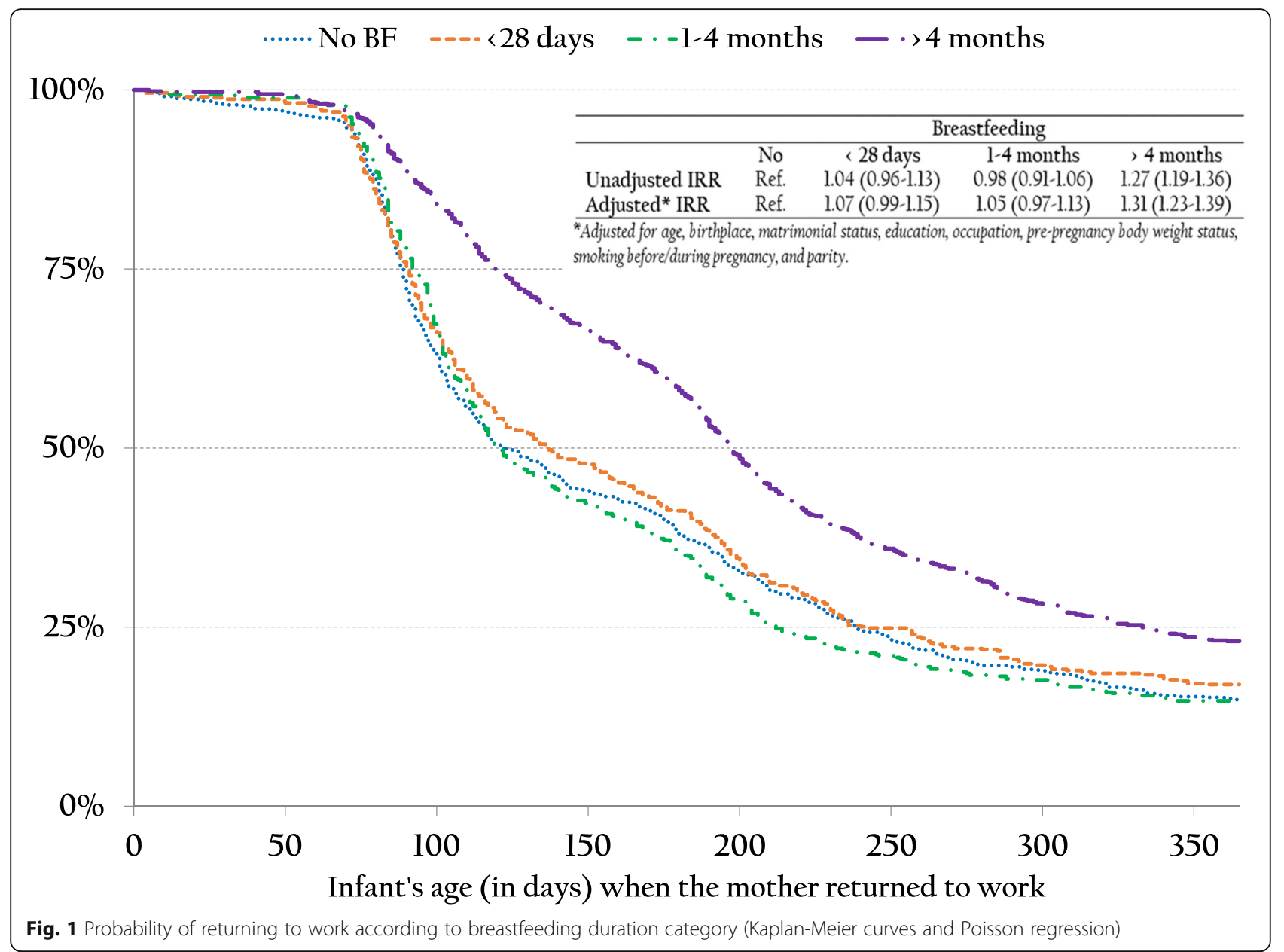

level (high school: 1.10 [1.03-1.17]; elementary/middle school: 1.14 [1.06-1.24]), intermediate employment (1.10 [1.03-1.17]) or manual work (1.27 [1.15-1.41]), overweight (1.08 [1.02-1.15]) or obesity (1.13 [1.06-1.21]) before pregnancy, smoking before and during pregnancy (1.13 [1.06-1.21]) and multiparity (2 deliveries: 1.23 [1.16-1.30]; $\geq 3$ deliveries: 1.48 [1.37-1.59]) remained statistically associated with later time of RTW (Table 2). When ABF duration instead of categories was included as a continuous variable in months, the adjusted IRR for time of RTW (in days) was $1.03[1.02-1.04](p<0.0001)$.

When analyses were performed using non-imputed variables for RTW and ABF, results were comparable. However, RTW time was significantly increased by $10 \%$ for $A B F$ duration shorter than 1 month (aRRR: 1.10 [1.02-1.20]) (this aRRR was close to statistical significance when imputed variables were used: 1.07 [0.99-1.15] - Table 2).

\section{Characteristics associated with combination of breastfeeding and work}

In women likely to combine $\mathrm{ABF}$ and work during the first year $(n=1487), 34.5 \%$ actually did so before the end of the first year. Most women who continued to breastfeed after RTW had exclusively breastfed at birth (93.7\%), compared to $75.2 \%$ of those who ceased to breastfeed before RTW. Likewise, they significantly exclusively breastfed for a much longer duration (median number of days: 76 days vs. 10 days) or not (213 days vs. 61 days) (Table 3). At 1 and 4 months, the total number of feeds given was statistically higher than in women who ceased ABF before RTW (about one feed per day) (Table 3). At the same ages, infants of women who continued to breastfeed after RTW were significantly less likely to sleep in their own bedrooms, but rather in the parents' bed or bedroom (Table 3).

According to final multivariate logistic regression (Table 4), women born outside of France (aOR: 2.24 [1.49-3.36]) and farmwomen, artisans and merchants (versus managers: 2.23 [1.11-4.47]) were more likely to continue to breastfeed after RTW. Moreover, women who were intermediate employees (versus managers: 0.58 [0.44-0.76]) or manual workers $(0.48$ [0.27-0.88]), who had been smokers before pregnancy, whether quitting during pregnancy (versus non-smokers before pregnancy: $0.61[0.44-0.84])$ or not $(0.49$ [0.32-0.76]), and those who underwent cesarean section $(0.69[0.50-0.96])$, 
Table 2 Association between women's characteristics and time of return to work (Poisson regressions; $n=2480$ )

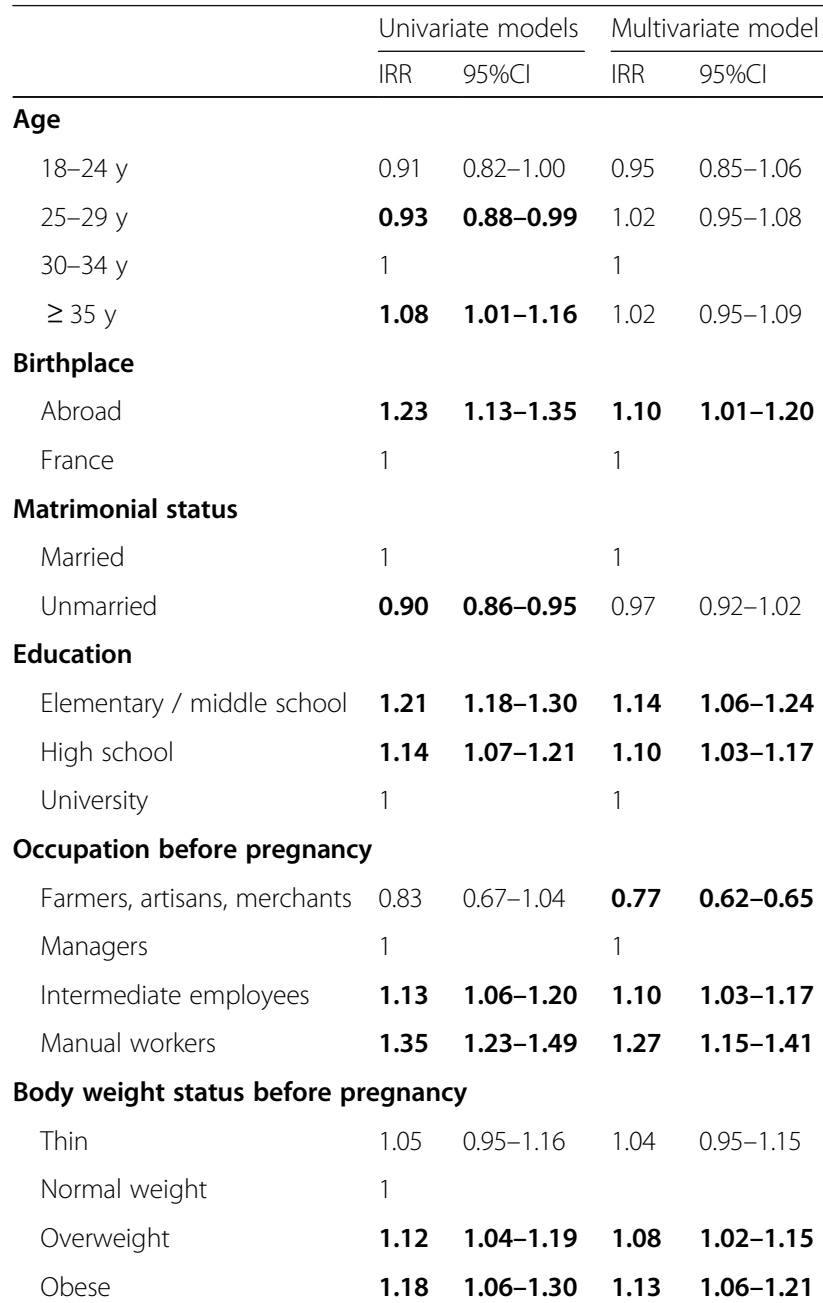

Smoking before pregnancy

$\begin{array}{lllll}\text { No } & 1 & & 1 & \\ \text { Quit during pregnancy } & 0.94 & 0.87-1.00 & 1.02 & 0.95-1.09 \\ \begin{array}{l}\text { Before \& during pregnancy } \\ \text { Parity }\end{array} & \mathbf{1 . 1 1} & \mathbf{1 . 0 3 - 1 . 1 9} & \mathbf{1 . 1 3} & \mathbf{1 . 0 6 - 1 . 2 1} \\ 1 & & & & \\ 2 & 1 & & 1 & \\ \geq 3 & \mathbf{1 . 2 6} & \mathbf{1 . 1 9 - 1 . 3 4} & \mathbf{1 . 2 3} & \mathbf{1 . 1 6 - 1 . 3 0} \\ & \mathbf{1 . 5 8} & \mathbf{1 . 4 8 - 1 . 6 9} & \mathbf{1 . 4 8} & \mathbf{1 . 3 7 - 1 . 5 9}\end{array}$

BF durations

\begin{tabular}{lllll} 
No BF & 1 & \multicolumn{3}{c}{1} \\
$<1$ month & 1.04 & $0.96-1.13$ & 1.07 & $0.99-1.15$ \\
$1-4$ months & 0.98 & $0.91-1.06$ & 1.05 & $0.97-1.13$ \\
$>4$ months & $\mathbf{1 . 2 7}$ & $\mathbf{1 . 1 9 - 1 . 3 5}$ & $\mathbf{1 . 3 1}$ & $\mathbf{1 . 2 3 - 1 . 3 9}$ \\
\hline
\end{tabular}

$B F$ breastfeeding, $C l$ confidence interval, IRR incidence rate ratio

were less likely to continue breastfeeding after RTW. When using non-imputed RTW time and ABF duration, the same ORs were estimated in this final model (data not shown).

\section{Discussion}

In our study carried out in France in 2012, eight out of ten employed women returned to work within a year, at a median of 5.3 months. We showed that no BF and $\mathrm{ABF}$ durations shorter than 4 months were associated with similar trends in RTW. Only women who breastfed for over 4 months returned to work at a later time. Furthermore, among breastfeeding women who returned to work within a year after delivery, one-third combined $\mathrm{ABF}$ and work. Birthplace, occupation, smoking status and mode of delivery were independently associated with combined $\mathrm{ABF}$ and work.

Comparison with other studies is limited due to variable durations of follow-up and different methods used to assess BF and work status. In our study, we used prospective repeated phone interviews for a one-year period to collect detailed information on infant feeding, which was the primary goal of the Epifane cohort [32]. In other studies using cross-sectional investigation, BF practice assessment was likely to lead to memory bias, especially when the interview was distant from the period in question. In contrast, we collected sparsely detailed information on work conditions after delivery. Other authors examined working status before pregnancy [21, 35], intention to return to work (not necessarily followed up) $[9,11,23,36]$, and various categories of time spans before RTW [6, 8-10, 15, 24]. In addition, groups of reference may have included mothers working before pregnancy, or not working at all, thereby affecting interpretation. In our study, we analyzed women who worked before pregnancy, enabling a more accurate interpretation. Moreover, since the RTW span is highly variable, it was considered here to be the outcome in survival analysis, thus enabling us to consider its potential determinants.

In our study, consistent with previous findings in other cohorts [8-10], ABF longer than 4 months was associated with a RTW 2 months later than for no ABF. It is difficult to determine whether women continued ABF because they were given the opportunity not to return to work before 4 months, or whether they chose to return to work later because they wished to breastfeed longer [37]. Nevertheless, Kaplan-Meier curves show no clear break at the end of the minimal legal maternity leave in France ( 12 weeks). In reality, paid maternity leave may vary under different circumstances, including legal provisions, i.e. shorter than 12 weeks for women who are self-employed, longer for women who have twins, a third pregnancy or major medical complications, women who postpone part of the prenatal leave after birth or who take annual leave, or have other favorable conditions agreed upon with their employer. The French situation is not transposable to all settings, which depend on the legal environment [2]. In-depth interviews are needed to 
Table 3 Breastfeeding and infant sleeping practices of women who continued to breastfeed after returning to work, compared with women who stopped breastfeeding before returning to work $(n=1487)$

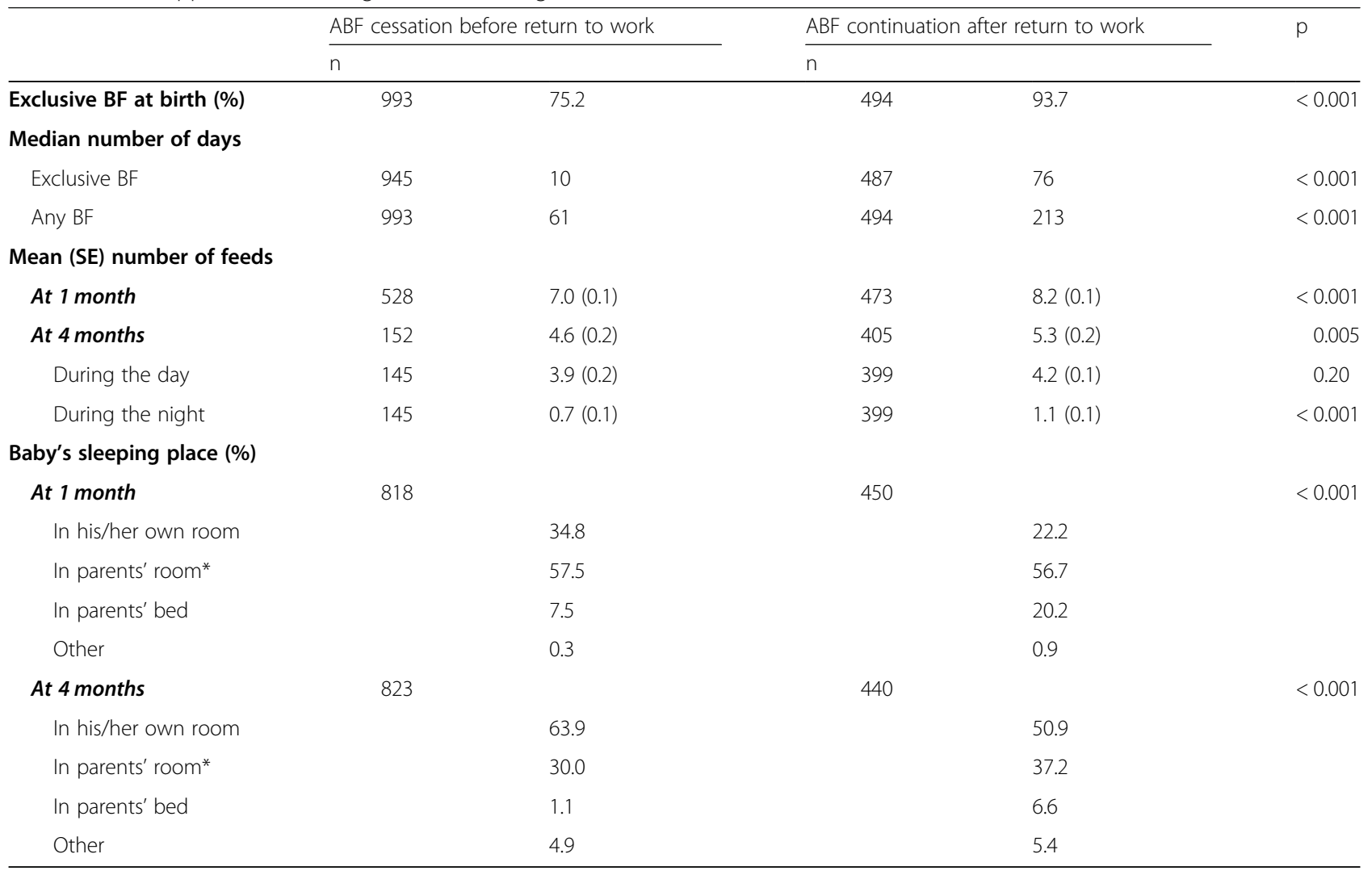

*But not in parents' bed. $A B F$ any breastfeeding, $B F$ breastfeeding, $S E$ standard error

better understand how work constraints influence the individual decision to breastfeed.

Another insightful finding was RTW time statistically comparable between women who did not breastfeed at all and those who breastfed for less than 4 months. Therefore, we hypothesize that BF initiation may not necessarily be dependent on a planned RTW $[2,36]$. Determinants of BF initiation other than planned RTW should therefore be taken into account. For instance, pregnancy complications are considered to be strong determinants of BF initiation [4,38], but they did not affect the RTW time in our study. "Farmwomen, artisans and merchants" were likely to return to work much earlier, but they were also more prone to breastfeeding for a longer duration. Flexibility in working hours therefore appears to be a key determinant in BF initiation and continuation [30]. In addition to occupation, full-time or part-time work status may also be a decisive factor, as shown in previous studies $[39,40]$. Such information was not available here, and our goal was to identify general characteristics of women who combined BF and work.

Indeed, women who combined BF and work showed significant specificities. First, exclusive BF since birth and on demand (loosely based on the number of feeds and on where the child slept) (Table 3) might augment the possibility of continuing BF after RTW. Second, selfemployed women who may have some flexibility ("Farmers, artisans and merchants") were most likely to continue BF. In contrast, manual workers and "intermediate employees" (i.e. with subordinate positions) were less likely to be able to continue ABF [41]. In an intermediate situation, and despite early RTW and other working constraints, managers may have continued ABF because it was compatible with their work organization and also because of the health benefits they expected for their child. The fact that, in our study, women who continued to breastfeed after RTW were more likely to be non-smokers before pregnancy also underlines a potentially higher degree of health awareness.

Though they were less likely to return to work within the child's first year, women born outside of France were more likely to combine $\mathrm{ABF}$ and work, regardless of other co-variates. Birthplace abroad was previously highlighted as a prominent BF determinant in developed countries [42]: community norms and dissemination across generations may account for such findings. Thus, ABF behavior of foreign women who return to work 
Table 4 Association between women and pregnancy characteristics and continuing BF after return to work (logistic regressions; $n=$ 1487)

\begin{tabular}{|c|c|c|c|c|}
\hline & \multicolumn{2}{|c|}{ Univariate models } & \multicolumn{2}{|c|}{ Final multivariate model } \\
\hline & $\overline{O R}$ & $95 \% \mathrm{Cl}$ & $\overline{O R}$ & $95 \% \mathrm{Cl}$ \\
\hline \multicolumn{5}{|l|}{ Age } \\
\hline $18-24$ y & 0.63 & $0.39-1.02$ & & \\
\hline $25-29 y$ & 0.74 & $0.57-0.98$ & & \\
\hline $30-34$ y & 1 & & & \\
\hline$\geq 35$ y & 1.01 & $0.74-1.39$ & & \\
\hline \multicolumn{5}{|l|}{ Birthplace } \\
\hline Abroad & 2.28 & $1.55-3.36$ & 2.24 & $1.49-3.36$ \\
\hline France & 1 & & 1 & \\
\hline \multicolumn{5}{|l|}{ Matrimonial status } \\
\hline Married & 1 & & & \\
\hline Unmarried & 0.71 & $0.57-0.90$ & & \\
\hline \multicolumn{5}{|l|}{ Education } \\
\hline Elementary / middle school & 0.74 & $0.49-1.12$ & 0.91 & $0.59-1.42$ \\
\hline High school & 0.57 & $0.41-0.79$ & 0.74 & $0.52-1.04$ \\
\hline University & 1 & & $1^{*}$ & \\
\hline \multicolumn{5}{|l|}{ Occupation before pregnancy } \\
\hline Farmers, artisans, merchants & 1.82 & $0.96-3.46$ & 2.23 & $1.11-4.47$ \\
\hline Managers & 1 & & 1 & \\
\hline Intermediate employees & 0.52 & $0.40-0.68$ & 0.58 & $0.44-0.76$ \\
\hline Manual workers & 0.43 & $0.25-0.73$ & 0.48 & $0.27-0.88$ \\
\hline \multicolumn{5}{|c|}{ Body weight status before pregnancy } \\
\hline Thin & 1.36 & $0.86-2.15$ & & \\
\hline Normal weight & 1 & & & \\
\hline Overweight & 1.05 & $0.77-1.42$ & & \\
\hline Obese & 0.87 & $0.54-1.39$ & & \\
\hline \multicolumn{5}{|l|}{ Smoking before pregnancy } \\
\hline No & 1 & & 1 & \\
\hline Quit during pregnancy & 0.57 & $0.41-0.78$ & 0.61 & $0.44-0.84$ \\
\hline Before \& during pregnancy & 0.38 & $0.25-0.57$ & 0.49 & $0.32-0.76$ \\
\hline \multicolumn{5}{|l|}{ Parity } \\
\hline 1 & 1 & & & \\
\hline 2 & 1.18 & $0.92-1.51$ & & \\
\hline$\geq 3$ & 1.23 & $0.85-1.78$ & & \\
\hline \multicolumn{5}{|l|}{ Mode of delivery } \\
\hline Vaginal & 1 & & 1 & \\
\hline Cesarean & 0.72 & $0.52-0.98$ & 0.69 & $0.50-0.96$ \\
\hline \multicolumn{5}{|l|}{ Gestational age } \\
\hline$\geq 37$ weeks & 1 & & & \\
\hline 33-36 weeks & 0.79 & $0.42-1.48$ & & \\
\hline \multicolumn{5}{|l|}{ Birthweight } \\
\hline$\geq 2500 \mathrm{~g}$ & 1 & & & \\
\hline$<2500 \mathrm{~g}$ & 0.54 & $0.27-1.05$ & & \\
\hline
\end{tabular}

*Covariate kept in the final multivariate model, since removing it modified the OR of "Workers" by more than $10 \%$. $\mathrm{Cl}$ confidence interval, $O R$ odds ratio 
would appear to be influenced by such conditions. The manner in which they succeed in combining ABF and work could help in developing actions destined for native-born mothers.

The primary objective of the Epifane cohort was to describe infant feeding during the first year of life. We therefore collected extremely detailed information [32]. However, information related to maternal working conditions is more limited, as underlined above. Moreover, though a large set of co-variates was taken into account, we cannot rule out residual confounding in the relationship between BF duration and RTW time, such as breastfeeding intentions, encouragement for breastfeeding (from the family, etc.), and income, which were not collected in this cohort. In addition, due to the short duration of exclusive BF in France, its specific analysis was not carried out, although this represents a target to be attained. Finally, despite strict instructions given to interviewers not to influence mothers, repeated questions on BF may have modified related behavior and yielded an overestimated percentage of women combining $\mathrm{ABF}$ and work. Finally, our results require confirmation by further studies in other settings.

\section{Conclusion}

Our findings may have important consequences for BF promotion. In contrast to generally held ideas, RTW does not necessarily prevent BF initiation or continuation, although this phenomenon is measurable only for BF duration of less than 4 months. Moreover, only onethird of women succeeded in combining work and BF. Indeed, working conditions, as described in our study via occupational categories, would appear to be of crucial importance. Finally, much improvement is needed in research, and at the public health level, so as to include widespread dissemination of information directed toward women who wish to continue breastfeeding after returning to work.

\section{Supplementary information}

Supplementary information accompanies this paper at https://doi.org/10. 1186/s12884-020-2801-x

Additional file 1: Table S1. Any breastfeeding (ABF) duration category according to characteristics of women who worked before pregnancy, Epifane Birth Cohort, $2012(n=2480)$.

\section{Abbreviations}

ABF: Any breastfeeding; BF: Breastfeeding; Cl: Confidence interval; IRR: Incidence rate ratios; OR: Odds ratio; RTW: Return to work; SE: Standard error

\section{Acknowledgements}

The authors are grateful to the midwives who contributed to data collection in the maternity wards and to parents who participated in the survey. They are also grateful to Catherine de Launay and Caroline Guerrisi (Esen, Santé
Publique France), who contributed to data monitoring and descriptive analyses. They thank Jerri Bram for English editing.

\section{Authors' contributions}

$\mathrm{KC}$ designed and conducted the research, conceptualized the statistical plan, interpreted the findings, drafted the initial manuscript, and reviewed and revised the manuscript. JBB contributed to the research and interpretation of findings, and reviewed and revised the manuscript. BS designed and conducted the research, carried out statistical analyses, and reviewed and revised the manuscript. The author(s) read and approved the final manuscript.

\section{Funding}

This survey was funded by the French Public Health Agency (Agence nationale de santé publique) and Paris-13 University. Julie Boudet-Berquier was the recipient of a doctoral grant from the Ministère de l'Enseignement Supérieur et de la Recherche, Paris, France and the Ecole des Hautes Etudes en Santé Publique (EHESP, Rennes, France). Funders were not involved in the design of the study, collection, analysis or interpretation of data, nor in the writing of the manuscript.

\section{Availability of data and materials}

The datasets used and/or analyzed during the current study are available from the corresponding author on reasonable request.

\section{Ethics approval and consent to participate}

The Epifane cohort project was approved by the Committee for Data Processing in Health Research (CCTIRS, registration $\left.n^{\circ} 11.335\right)$ and the French Data Protection Authority (CNIL, authorization n911,299). The written consent-to-participate form was filled in by women included in the cohort after birth, with an explanatory letter concerning the aims of the study.

\section{Consent for publication}

Not applicable.

\section{Competing interests}

The authors have no conflicts of interest to disclose. The authors have no financial relationships to disclose relevant to this article.

\section{Author details}

'Université libre de Bruxelles, Ecole de Santé Publique, Centre de Recherche en Epidémiologie, Biostatistique et Recherche Clinique, CP 598, Université libre de Bruxelles, Route de Lennik, 808, B-1070 Bruxelles, Belgium. ${ }^{2}$ Equipe de Surveillance et d'Epidémiologie Nutritionnelle (Esen), Santé Publique France, Université Paris 13, Centre de Recherche en Epidémiologie et Statistiques, COMUE Sorbonne Paris Cité, Bobigny, France. ${ }^{3}$ Département des Maladies Non Transmissibles et Traumatismes (DMNTT), Santé Publique France, Saint Maurice, France.

Received: 29 January 2019 Accepted: 10 February 2020

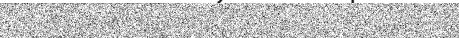

\section{References}

1. Victora CG, Bahl R, Barros AJD, França GVA, Horton S, Krasevec J, et al. Breastfeeding in the 21st century: epidemiology, mechanisms, and lifelong effect. Lancet. 2016;387:475-90.

2. Andres E, Baird S, Bingenheimer JB, Markus AR. Maternity leave access and health: a systematic narrative review and conceptual framework development. Matern Child Health J. 2016;20:1178-92.

3. O'Gara C, Canahuati J, Martin AM. Every mother is a working mother: breastfeeding and women's work. Int J Gynaecol Obstet. 1994;47(Suppl): S33-8 discussion S38-39.

4. Rollins NC, Bhandari N, Hajeebhoy N, Horton S, Lutter CK, Martines JC, et al. Why invest, and what it will take to improve breastfeeding practices? Lancet. 2016:387:491-504.

5. Amiel Castro RT, Glover V, Ehlert U, O'Connor TG. Antenatal psychological and socioeconomic predictors of breastfeeding in a large community sample. Early Hum Dev. 2017;110:50-6.

6. The "EDEN Mother-Child Cohort Study Group", Bonet M, Marchand L, Kaminski M, Fohran A, Betoko A, et al. Breastfeeding Duration, Social and 
Occupational Characteristics of Mothers in the French 'EDEN Mother-Child' Cohort. Matern Child Health J. 2013;17:714-22.

7. Dagher RK, McGovern PM, Schold JD, Randall XJ. Determinants of breastfeeding initiation and cessation among employed mothers: a prospective cohort study. BMC Pregnancy Childbirth. 2016;16. https://doi. org/10.1186/s12884-016-0965-1.

8. Cox K, Binns CW, Giglia R. Predictors of breastfeeding duration for rural women in a high-income country: evidence from a cohort study. Acta Paediatr. 2015;104:e350-9.

9. Hauff $L E$, Leonard SA, Rasmussen KM. Associations of maternal obesity and psychosocial factors with breastfeeding intention, initiation, and duration. Am J Clin Nutr. 2014;99:524-34.

10. Hawkins SS, Griffiths $\sqcup$, Dezateux C. Catherine law and the millennium cohort study child health group. The impact of maternal employment on breast-feeding duration in the UK millennium cohort study. Public Health Nutr. 2007;10. https://doi.org/10.1017/S1368980007226096.

11. Mirkovic KR, Perrine CG, Scanlon KS. Paid maternity leave and breastfeeding outcomes. Birth. 2016;43:233-9.

12. Ogbuanu C, Glover S, Probst J, Liu J, Hussey J. The effect of maternity leave length and time of return to work on breastfeeding. Pediatrics. 2011;127: e1414-27.

13. Smith HA, O'B Hourihane J, Kenny LC, Kiely M, Murray DM, Leahy-Warren P. Early life factors associated with the exclusivity and duration of breast feeding in an Irish birth cohort study. Midwifery. 2015;31:904-11.

14. Villar M, Santa-Marina L, Murcia M, Amiano P, Gimeno S, Ballester F, et al. Social factors associated with non-initiation and cessation of predominant breastfeeding in a mother-child cohort in Spain. Matern Child Health J. 2018:22:725-34

15. Xiang $\mathrm{N}$, Zadoroznyj $\mathrm{M}$, Tomaszewski W, Martin B. Timing of return to work and breastfeeding in Australia. Pediatrics. 2016;137:e20153883.

16. Brown CRL, Dodds L, Legge A, Bryanton J, Semenic S. Factors influencing the reasons why mothers stop breastfeeding. Can J Public Health. 2014;105: e179-85.

17. Guelinckx I, Devlieger R, Bogaerts A, Pauwels S, Vansant G. The effect of prepregnancy BMl on intention, initiation and duration of breast-feeding. Public Health Nutr. 2012:15:840-8.

18. Mandal B, Roe BE, Fein SB. The differential effects of full-time and part-time work status on breastfeeding. Health Policy. 2010:97:79-86.

19. Schwartz K, D'Arcy HJS, Gillespie B, Bobo J, Longeway M, Foxman B. Factors associated with weaning in the first 3 months postpartum. J Fam Pract. 2002;51:439-44

20. Tarrant M, Fong DYT, Wu KM, Lee ILY, Wong EMY, Sham A, et al. Breastfeeding and weaning practices among Hong Kong mothers: a prospective study. BMC Pregnancy Childbirth. 2010;10:27.

21. Attanasio L, Kozhimannil KB, McGovern P, Gjerdingen D, Johnson PJ. The impact of prenatal employment on breastfeeding intentions and breastfeeding status at 1 week postpartum. J Hum Lact. 2013;29:620-8.

22. Bulk-Bunschoten AM, van Bodegom S, Reerink JD, Pasker-de Jong PC, de Groot CJ. Reluctance to continue breastfeeding in the Netherlands. Acta Paediatr. 2001;90:1047-53.

23. Noble S. ALSPAC study team. Avon longitudinal study of pregnancy and childhood. Maternal employment and the initiation of breastfeeding. Acta Paediatr. 2001:90:423-8.

24. Logan C, Zittel T, Striebel S, Reister F, Brenner H, Rothenbacher D, et al. Changing societal and lifestyle factors and breastfeeding patterns over time. Pediatrics. 2016;137:e20154473.

25. Hawkins SS, Griffiths L. Dezateux C, law C, millennium cohort study child health group. Maternal employment and breast-feeding initiation: findings from the millennium cohort study. Paediatr Perinat Epidemiol. 2007;21:242-7.

26. Chuang C-H, Chang P-J, Chen Y-C, Hsieh W-S, Hurng B-S, Lin S-J, et al. Maternal return to work and breastfeeding: a population-based cohort study. Int J Nurs Stud. 2010;47:461-74.

27. Pitonyak JS, Jessop AB, Pontiggia L, Crivelli-Kovach A. Life course factors associated with initiation and continuation of exclusive breastfeeding. Matern Child Health J. 2016;20:240-9.

28. Mangrio E, Persson K, Bramhagen A-C. Sociodemographic, physical, menta and social factors in the cessation of breastfeeding before 6 months: a systematic review. Scand J Caring Sci. 2018;32:451-65.

29. Bai DL, Fong DYT, Tarrant M. Factors associated with breastfeeding duration and exclusivity in mothers returning to paid employment postpartum. Matern Child Health J. 2015;19:990-9.
30. Dinour LM, Szaro JM. Employer-based programs to support breastfeeding among working mothers: a systematic review. Breastfeed Med. 2017;12:131-41.

31. Position of the American Dietetic Association. Promoting and supporting breastfeeding. J Am Diet Assoc. 2009;109:1926-42.

32. Boudet-Berquier J, Salanave B, de Launay C, Castetbon K. Introduction of complementary foods with respect to French guidelines: description and associated socio-economic factors in a nationwide birth cohort (Epifane survey). Matern Child Nutr. 2017;13:e12339.

33. World Health Organization (WHO). Indicators for assessing infant and young child feeding practices: conclusions of a consensus meeting held 6-8 November 2007 in Washington D.C., USA. Washington, D.C.: World Health Organization (WHO); 2008.

34. Blondel B, Coulm B, Bonnet C, Goffinet F, Le Ray C. National Coordination Group of the National Perinatal Surveys. Trends in perinatal health in metropolitan France from 1995 to 2016: results from the French National Perinatal Surveys. J Gynecol Obstet Hum Reprod. 2017;46:701-13.

35. Fein SB, Mandal B, Roe BE. Success of Strategies for Combining Employment and Breastfeeding. Pediatrics. 2008;122(upplement 2):S56-62.

36. Scott JA, Aitkin I, Binns CW, Aroni RA. Factors associated with the duration of breastfeeding amongst women in Perth. Australia Acta Paediatr. 1999;88: 416-21.

37. Roe B, Whittington LA, Fein SB, Teisl MF. Is there competition between breast-feeding and maternal employment? Demography. 1999;36:157-71.

38. Prior E, Santhakumaran S, Gale C, Philipps LH, Modi N, Hyde MJ. Breastfeeding after cesarean delivery: a systematic review and meta-analysis of world literature. Am J Clin Nutr. 2012:95:1113-35.

39. Kurinij N, Shiono PH, Ezrine SF, Rhoads GG. Does maternal employment affect breast-feeding? Am J Public Health. 1989;79:1247-50.

40. Mirkovic KR, Perrine CG, Scanlon KS, Grummer-Strawn LM. Maternity leave duration and full-time/part-time work status are associated with US mothers' ability to meet breastfeeding intentions. J Hum Lact. 2014;30:4169.

41. Steurer LM. Maternity leave length and workplace policies' impact on the sustainment of breastfeeding: global perspectives. Public Health Nurs. 2017; 34:286-94.

42. Bonet M, Blondel B, Khoshnood B. Evaluating regional differences in breastfeeding in French maternity units: a multilevel approach. Public Health Nutr. 2010;13:1946-54.

\section{Publisher's Note}

Springer Nature remains neutral with regard to jurisdictional claims in published maps and institutional affiliations.

Ready to submit your research? Choose BMC and benefit from:

- fast, convenient online submission

- thorough peer review by experienced researchers in your field

- rapid publication on acceptance

- support for research data, including large and complex data types

- gold Open Access which fosters wider collaboration and increased citations

- maximum visibility for your research: over $100 \mathrm{M}$ website views per year

At BMC, research is always in progress.

Learn more biomedcentral.com/submission 